\title{
The Teaspoon Method; A Simple Training Program for Feeding Disorders in High Functioning Autistic Children
}

\author{
Ellen J. Van Der Gaag, Marlou C. E. Snijders \\ Department of Pediatrics, Hospital Group Twente, Hengelo, The Netherlands \\ Email: e.gaagvander@zgt.nl
}

How to cite this paper: Van Der Gaag, E.J. and Snijders, M.C.E. (2017) The Teaspoon Method; A Simple Training Program for Feeding Disorders in High Functioning Autistic Children. Open Journal of Pediatrics, 7, 59-71.

https://doi.org/10.4236/ojped.2017.72009

Received: March 2, 2017

Accepted: June 3, 2017

Published: June 6, 2017

Copyright (c) 2017 by authors and Scientific Research Publishing Inc. This work is licensed under the Creative Commons Attribution International License (CC BY 4.0).

http://creativecommons.org/licenses/by/4.0/

\begin{abstract}
Objective: About $90 \%$ of autistic children are known to have a selective feeding disorder. In particular, methods are lacking for stimulating self feeding and treating selective eating amongst school-aged and adolescent autistic children. We developed a simple training programme for paediatricians in a general hospital to improve the eating pattern of autistic children and decrease selectivity. Methods: The study is an experimental patient series. The instructions for the training were given in 15-minute sessions by a paediatrician with the use of social positive and negative reinforcements. The negative reinforcement was an avoidance situation. The training was performed with parental participation in the home environment of the child. Results and conclusion: In the before and after measurement, the quantitative intake of fruit, potatoes and vegetables increased significantly $(\mathrm{p}<0.05)$. Food selectivity decreased, expressed by an increase in variation of consumed fruit, meat, potatoes and sandwich filling $(\mathrm{p}<0.01)$. The costs of the training are low, and the children stay in their home environment.
\end{abstract}

\section{Keywords}

Autism, Feeding Disorders, Children, Parents

\section{Introduction}

Feeding disorders are very common in autistic children. This is due, amongst others, to sensory abnormalities, rigid eating habits and a resistance to try new foods [1] [2]. The most commonly reported problem is food selectivity [3]. The selective diets of children with autism are often high in fat and/or sodium and low in nutritional content. The consistent and rigid eating patterns ensure that the child feels in control, but the variety of food eaten tends to narrow over the 
years. It is not uncommon for pediatricians to recommend that parents wait for their child to "grow out of" selectivity issues [4]. However, Schreck et al. interviewed caregivers of children up to the age of 12 and their results indicated that children with autism do not "grow out of" feeding problems [3].

Besides the selectivity, some parents mention that their autistic child seems not to recognize the feeling of hunger; they seem to have a permanently inhibited appetite. They do not ask for food, and can forget to eat the entire day when the parents do not offer their child something to eat. Recent studies found elevated levels of leptin in autistic patients, which could possibly explain the appetite inhibition [5] [6]. The appetite inhibition due to high levels of leptin is usually long-term, in contrast to the rapid inhibition of hunger due to other hormones (cholecystokinin or PYY3-36). With long-term absence of appetite, they cannot rely on appetite as an internal motivation to eat, but are largely dependent on extrinsic motivation.

If the feeding disorder is mild, parents usually learn to live with it. Most of the time, one of the parents recognizes a self characteristic in their child; "I also don't like yoghurt with pieces of fruit", or "I don't like vegetables either". At the other end of the spectrum, the very severely restricted feeding disorder usually requires intensive treatment in an outpatient setting or an inpatient treatment for several weeks/months [7] [8]. However, this intensive treatment is not available or suitable for every child. Regardless of the origin of the feeding disorder, there are two major consequences that become apparent. The first is a result of the lack of variation in the dietary habits; it is often too fat and/or high in sodium and low in nutritional content. These children usually develop nutrient deficiencies with consequences for their future health [9] [10]. Vitamin D deficiency is usually present, although vitamin B12, magnesium and iron are other elements that can become deficient [11] [12]. The second consequence is the impact on the functioning of the family. Children with severe autistic disorders cause high stress situations for the family at mealtimes and parents tend to adjust their (cooking) behavior to the child [13] [14]. However, one should be aware of the attitude of the parents. When parents become too permissive and cook especially for the child, they are apt to serve only familiar food and the feeding disorder can deteriorate further. This is due to the permissiveness of the parents [15].

Positive reinforcement works by presenting a motivating/reinforcing stimulus to the person after the desired behaviour is exhibited, making the behaviour more likely to happen in the future. Negative reinforcement occurs when the rate of a behaviour increases because an aversive event or stimulus is removed or prevented from happening. With negative reinforcement, a behavior is increased, whereas with punishment, a behavior is decreased. Piazza et al. systematically evaluated how caregiver consequences such as escape, adult attention and giving the child a tangible item affected child behaviour during meals using a procedure called functional analysis [16]. Results suggested that providing escape, delivering adult attention, or giving a tangible item following inappropriate 
mealtime behaviour actually worsened this behaviour amongst most children. In functional analysis, the role of negative reinforcement is controversial. In $90 \%$ of the cases, escape from eating maintained inappropriate behaviour highlighting the role of negative reinforcement in the maintenance of feeding problems. In a study by Najdowski et al., the results of functional analyses for five children with autism indicated that escape functioned as a negative reinforcement for inappropriate mealtime behaviour [17]. However, in some patients good results cannot be obtained without the use of negative reinforcement. Vaz et al. showed the use of not only a positive approach, but also the benefit of negative reinforcement, especially when the child lacks motivation to eat [18]. The therapists fed the patient avoidance foods after a bite of the target food which the patient refused to eat willingly. Once confronted with the avoidance foods, the patient showed high acceptance rates for the target foods; the consequences of self-feeding were presumably more favourable than the consequences of being fed.

We tried to develop a method involving parental participation, in which the parents could better manage their child's feeding problem and introduce new dietary habits. The method is designed for autistic children, who do not respond or react to a positive approach. Despite the mentioned negative results of the (most unconscious) caregiver consequences, we used negative reinforcement as a consequence, to increase desired feeding behaviour, since positive reinforcement did not work in our patients.

\section{Methods}

\subsection{Patients}

The children (aged 3 - 14 years) all visited a general pediatrician because of feeding disorders. The study was performed in a general hospital in the eastern part of the Netherlands. Inclusion criteria were the following: the child should be diagnosed with ASD (Autism Spectrum Disorder) and should have a feeding disorder characterized by selective eating, absence of appetite or rigid eating patterns, not responding to positive reinforcements. More than three food groups (bread, fruit, vegetables, etc.) should be refused systematically. We selected high functioning autistic children; high functioning was defined as children living with their parents who attended regular school (with the exception of the three year old). Most of them were self-feeding, but when they were spoonfed, this was not an exclusion criterium.

\subsection{Measurements}

At inclusion, we evaluated the actual health of the child. We performed laboratory research for somatic disorders which could explain the feeding disorder (celiac disease, food allergy or food intolerance, parasitic infections of the intestine). We also searched for deficiencies caused by the selective food intake (e.g. iron deficiency, complete blood count, erythrocyte morphology or vitamin D deficiency). 
Weight and height were measured on the same weighing scale and size measurement device by the pediatrician. BMI was calculated based on these values.

The caregivers kept a food log of which food groups the child ate. The quantity of the food group was measured in spoons: 1 teaspoon $(5 \mathrm{ml}=0.17 \mathrm{fl} \mathrm{oz}), 1$ tablespoon $(15 \mathrm{ml}=0.5 \mathrm{fl} \mathrm{oz})$. The quantity of the food group was good if the child ate the food group according to the recommended daily allowance (for a toddler three tablespoons ( $45 \mathrm{ml}=1.5 \mathrm{fl} \mathrm{oz}$ ) of vegetables a day) [19]. Variation was good if the child was not restricted to a few products, but ate more than five products of that food group.

\subsection{Theoretical Background}

The basic principle of the training is that eating is a normal and natural requirement. When the parent asks the child to eat, this is a normal activity nothing special, nothing worth a big reward or present when the child starts eating. We teach the parents and the child the basic principles of the need for nutrition: "Eating is normal. Everybody has to eat, you are not an exception. When you don't like food, you don't wait for the feeling when you want to eat. You eat because your body needs the food. When you don't eat, your body becomes unhealthy. Your body cannot play or work. You will not grow and therefore stay small". The parents can choose arguments to which their child is sensitive.

The child has several reasons not to eat, especially fears, sensory problems, absence of appetite and/or rigid patterns. All these reasons become thresholds for starting to eat. Their fears can be eased by taking very small steps (the amount of a teaspoon). We use these small steps to prevent them from panicking and to help them overcome their thresholds.

Despite the described negative results on mealtime behaviour of the caregiver consequences like escape or delivering adult attention, we used a combination of positive and negative reinforcement as a consequence, since positive reinforcement alone did not work in our patients. The negative reinforcement is not escape from the mealtime, but changes to an avoidable situation. We make the avoidable situation very unattractive, and the mealtime easier and more attractive by offering really small amounts of food and a positive reinforcement afterwards. For example, when they refused the vegetables, they went to bed without reading a story or watching television (whatever their bed-time routine), because they ate insufficient food and their body needed to rest. When they decided to eat the vegetables, they got out of bed and continued the meal. Subsequently, they returned to the standard bed-time routine. This, however, was not a reward; the standard routine continued as usual, since eating is a normal everyday habit which does not need rewarding. We used the same reinforcement consistently throughout the study.

We used the avoidance situation for all children, except for those whose comfort zone is their bedroom. Going to their bedroom would not be an avoidable situation. These children could, for example, have restricted or no access to elec- 
tronics (Wii, computer, tablet etc.).

\subsection{Training}

The child and the parents visited the general pediatrician at the outpatient clinic. The training was explained by the pediatrician to the child and the parents at the same time. They were all given the same information. We started with the food group the child needed most (proven deficiencies such as meat when an iron deficiency is present). Deficiencies due to absent or insufficient intake of vegetables are very difficult to detect with laboratory examination. When there is not a specific food type deficient, we start with vegetables. Almost all children ate no or a restricted amount of vegetables.

The approach to the child should be neutral. The assignments come from the pediatrician, not from the parents. In this way, the conflicts between the child and parents can decrease, because a "stranger" is in the lead. When the child gets angry, he cannot blame the parents, but a stranger. This gives the parents more space to perform the training. The assignment for the first month was for the child to eat the amount of one teaspoon of vegetables every day at dinnertime, in the home environment. They were not allowed to eat their preferred vegetables; they ate the same as the rest of the family. Only after eating a teaspoonful could they continue the meal as usual with their preferred food and receive a positive (social) reinforcement. When the child did not eat, they could choose the vegetables they wanted and continue the meal or go to the predefined avoidable situation. The child understood this situation. The child had a choice which they could reconsider one time, when in the avoidable situation. The teaspoon assignment occured once a day at dinnertime, every day for one month, until the next appointment with the pediatrician. All the other eating habits of the child remained unchanged at that point. This demanded great creativity and persistence from the parents; creativity to find an avoidable consequence, and persistence because the situation and training had to be repeated every day.

The following month, they received a new assignment. When they did not succeed, having fulfilled less than $50 \%$ of the first assignment, they repeated the same assignment with different consequences (other avoidable situations). When they did succeed, we increased the amount of vegetables to one tablespoon. Again, they ate with the rest of the family. Sometimes they were given their preferred vegetables, but most of the time their non-preferred vegetables. In the third month, we increased the amount to two tablespoons, and in the fourth month to three tablespoons of vegetables. In the fifth month, we switched to another food group the child did not eat-for example, dairy products, fruit or meat. We did not use the small amounts any more, as the children were now used to eating food they did not prefer. It was usually no longer necessary to take small steps. We then gave them assignments like a glass or half a glass of natural milk or half a portion of fruit. If the child did experience more problems with the introduction of a new food group, the decision was taken to start with small amounts. 
The first visit took 30 minutes (explanation of the training and first assignment), and the following visit was for 15 minutes (evaluation, measurement of height and weight, new assignment).

\subsection{Evaluation}

Primary outcome is an adequate amount of food eaten from a food group (age appropriate portions according to the Dutch Nutrition Centre [19]), and a decrease in the selectivity of that food group (more than five kinds of vegetables, for example). Secondary outcome is the growth (weight and length) and BMI (Body Mass Index).

\subsection{Statistics}

For statistical analysis, SPSS version 16.0 was used. Non-parametric tests (McNemar Test and Wilcoxon Signed Ranks Test) evaluated the change in BMI, and quantitative and qualitative intake before and after the training. Statistical analysis was not possible for all food groups in case none or all participants consumed that specific food group.

\section{Results}

\subsection{Patient Descriptives}

Twenty two children aged 3 - 14 years, and their parents agreed to participate in the training programme. Three children were excluded. One child was not a regular visitor to the outpatient clinic and valuable data were missing. One child (12 years of age) refused to continue after three visits because she could not be motivated by her doctor, parents or family. She would not eat and the parents did not use the consequences ("because it wouldn't work anyway"). One child (four years of age) was excluded because the parents refused to continue. They pitied their daughter and thought the consequence (going to bed) was too harsh. Nineteen children completed the training programme and were evaluated. $\mathrm{Pa}$ tient characteristics are described in Table 1.

\subsection{Laboratory Evaluation}

We investigated (micro-) nutrient deficiencies in our patients. Due to anxiety, not all patients were evaluated by laboratory research. Anaemia because of iron

Table 1. Baseline characteristics patient group.

\begin{tabular}{cc}
\hline characteristics & Patient group \\
\hline Mean age (years) & 7.8 \\
Boys: Girls & $12: 7$ \\
Food selectivity & $19 / 19(100 \%)$ \\
Weight to length $<-2 \mathrm{SD}$ & $6 / 19(31 \%)$ \\
Vitamin D insufficiency $(50-75 \mathrm{nmol} / \mathrm{l})$ & $10 / 13(77 \%)$ \\
Vitamin D deficiency $(<50 \mathrm{nmol} / \mathrm{l})$ & $3 / 13(23 \%)$ \\
Iron deficiency anemia $(<6.6 \mathrm{mmol} / \mathrm{l})$ & $3 / 15(20 \%)$ \\
\hline
\end{tabular}


deficiency was present in 3 of the 15 children (Hemoglobulin levels $<6.8$ $\mathrm{mmol} / \mathrm{l})$. Insufficient vitamin $\mathrm{D}$ levels were present in 10 of the 13 patients; three patients had deficient levels (vitamin $\mathrm{D}<50 \mathrm{nmol} / \mathrm{l}$ ) and seven showed insufficient levels (levels between $50-75 \mathrm{nmol} / \mathrm{l})$. Three patients showed adequate levels of vitamin D. Two of these three patients used vitamin D supplementation; the other patient ate dairy products (milk and dessert). Signs of celiac disease were not found in our population. All but one patient showed increased IgE levels, but no specific allergy for food products.

\subsection{Quantity and Variation}

The quantitative intake of all food groups increased (Table 2). Since the age appropriate portions increased with age, the actual size could not be compared. We noted whether the portion size was appropriate according to the recommendation of the Dutch Nutrition Centre [19]. If it was, the quantity was judged to be good. The total intake of fruit, potatoes and vegetables improved significantly ( $\mathrm{P}$ $<0.05)$. Statistical analysis was not possible for all food groups, since in some all children ate the food group. With a rate of $100 \%$, statistical calculations could not be made. The same was true for groups where no children ate adequately. Statistical calculations with $0 \%$ could not be performed.

The variation of the consumed food, almost a characteristic of an autistic feeding disorder, also improved significantly. Particularly, the variation in vegetables and fruit increased in almost all patients (Table 3). At the end of the training, there was only one child who did not eat any fruit, but he started eating fruit one month after finishing the training. All children ate potato or rice products, meat, vegetables and dairy products. Of the two children who did not eat dessert, their dairy consumption was from natural milk (not artificially flavoured). Surprisingly, when the assignment was to eat increasing amounts of vegetables, a side effect was seen in almost all children. They started to try spontaneously other food groups, without any assignment, eating, for example, bananas or fish sticks on their own initiative. The training took a mean of 7.5 months, with a variation between 3 and 17 months.

Table 2. The amount (slices of bread) or number of children who ate in accordance with the age-dependent portion sizes recommended by the Dutch Nutrition Centre, before and after the training.

\begin{tabular}{cccc}
\hline \multirow{2}{*}{ Food Group } & \multicolumn{3}{c}{ Eating normal portion sizes } \\
\cline { 2 - 4 } & Before training & After training & p-value \\
\hline Bread (slices a day) & 2.2 & 2.9 & \\
Fruit (any) & $12 / 19$ & $18 / 19$ & 0.031 \\
Potato products & $12 / 19$ & $19 / 19$ & $*$ \\
Meat (any) & $15 / 19$ & $19 / 19$ & $*$ \\
Vegetables (any) & $10 / 19$ & $19 / 19$ & $*$ \\
Dairy products (any) & $17 / 19$ & $19 / 19$ & $*$ \\
Dessert & $13 / 19$ & $17 / 19$ & 0.421 \\
\hline
\end{tabular}

${ }^{\star}$ Not possible to calculate with statistical analysis. 
Table 3. The variation in the consumed food before and after the training. Numbers indicate children who eat that specific food group AND are not selective. Not selective = eating $>5$ types of food of that food group in adequate age appropriate portions

\begin{tabular}{cccc}
\hline \multirow{2}{*}{ Food Group } & \multicolumn{3}{c}{ Not selective eating } \\
\cline { 2 - 4 } & Before training & After training & p-value \\
\hline Fruit & $4 / 19$ & $15 / 19$ & $<0.001$ \\
Potato products & $3 / 19$ & $12 / 19$ & $<0.01$ \\
Meat & $6 / 19$ & $15 / 19$ & $<0.01$ \\
Vegetables & $0 / 19$ & $16 / 19$ & $\star$ \\
Dairy products & $12 / 19$ & $16 / 19$ & 0.125 \\
Dessert & $9 / 19$ & $15 / 19$ & $<0.05$ \\
Sandwich filling & $7 / 19$ & $16 / 19$ & $<0.001$ \\
\hline
\end{tabular}

${ }^{*}$ Not possible to calculate with statistical analysis.

\subsection{Growth}

At the start of the training, six children were classed as underweight (weight to length $<-2 \mathrm{SD}$ ). After the training, only two children were underweight. In both children the weight to length increased, but it was still below the -2 SD values. At the other end, one child was obese at the start of the training (weight to length $>2 \mathrm{SD}$ ). At the end, she was still obese, but her weight to length decreased because of the altered composition of her diet (more vegetables). Another child grew from the normal range to the overweight range (weight to length between 2 - $2.5 \mathrm{SD}$ ). When she eventually started to eat, she found it difficult to stop eating. She ate much of everything. Through dieting she lost weight to the normal range. The mean BMI for all children before the training was 15.4, and increased to 16.2 after completion of the training ( $p 0.02$ ).

\section{Discussion}

The teaspoon method has been shown to be a simple and effective method to cope with feeding disorders in high functioning autistic children. Selective eating can be reversed, and the food intake can increase and become less rigid. The quantitative as well as the qualitative intake increased significantly in all children who participated in the study. The teaspoon method can be used by a general pediatrician or family physician since it combines medicinal (deficiencies and nutrition) and psychological aspects (how to reach appropriate behaviour in a patient). Since most medical doctors are not trained in psychology, we used well investigated and scientifically proven principles of behavioural techniques and applied behaviour analysis (ABA) [20]. The principles and results of ABA target real-life applications for the person they are working with. When the problem is created by the absence of appetite, the approach can also be aimed at the target (to eat healthy food) and not primarily to improve appetite. Food intake is of great value in real-life applications. In these cases, the motivation to change behavior should come from external factors, from the parents and/or care-takers of the child. Parental participation plays a key role in our approach. 
In particular, for school-aged and adolescent autistic children, methods for stimulating self feeding and treating selective eating are lacking. In younger age groups, well investigated methods can be applied such as physical guidance, escape extinction, noncontingent positive reinforcement, simultaneous presentation, stimulus fading or high probability instructional sequence [21].

Previous studies have shown that parents of autistic children can receive behavioral skills training with good results. The children's acceptance of bites increases and their disruptive behaviour decreases [22]. Therefore, by addressing the parents, the same approach can be adopted towards the child and, consequently, there is no interference from different types of health care professionals. Expensive treatment in institutions can be avoided when the parents adopt simple behavioural techniques to treat their child.

Similar to the results of $\mathrm{Vaz}$, the use of negative reinforcement did not worsen the feeding problem by providing an escape from the meal [18]. Vaz used consequences and negative reinforcement to stimulate self-feeding in a six-year-old typically developing child with a selective feeding disorder. The child was given 30 seconds to take the bite himself; if he did not, the therapist fed him one bite of target food and five bites of avoidance food. The consequences for self-feeding were more favourable than the consequences for not self-feeding, namely, being fed with more bites of avoidance food. In Vaz' study, the avoidance food was less preferred than the target food, which the child should learn to self-feed. In our investigation, we did not use avoidance food, but an avoidance situation. The consequences of taking the teaspoon with vegetables were more favourable than the consequences of not eating. The child should stay in his or her room, or have no access to preferred activities (like electronics). An interesting similar finding in the study of Vaz was that the child showed an immediate acceptance rate of $100 \%$ when the avoidance food was introduced. The child was exposed to this avoidance food in the pilot work of their study. We saw the same reaction in our children. When they did not take the teaspoon with vegetables, the avoidance situation was introduced. When they experienced it one or two times, the acceptance rate also increased to almost $100 \%$. There were always one or two types of vegetables the children really disliked and would, therefore, accept the consequence. However, after experiencing the avoidance situation the children knew that their parents were serious and would almost always choose to take the teaspoon.

If the child has a persistently selective feeding problem, we think it is justified to use negative reinforcements to prevent the physical condition from deteriorating. If the feeding disorder of the child continues, the risk of developing nutrient deficiencies increases. Previous studies of inadequate diets noted vitamin D, vitamin B12, iron and vitamin A deficiency [11] [12] [23] [24] [25]. Future health perspectives are less favourable and the quality of life perspective decreases. The consequences of nutrient deficiencies have been investigated before. Vitamin D deficiency results in higher incidences of acute respiratory infections [26], poorer lung function [27], dementia [28], early menarche with the risk of 
cardio metabolic disease and cancer [29]. Anemia and neurological symptoms develop in vitamin B12 deficiency [30] [31] [32]. Iron deficiency can result in sleeping disorders more than 10 years later in life, even with supplementation [33] [34]. The effects of vitamin A deficiency are well described in a Cochrane review; higher rates of mortality, diarrhea and morbidity from infections and also permanent visual loss due to optic atrophy [24] [35].

\section{Limitations}

A downside of our method is inappropriate use of consequences and motivating the child to choose, which could resemble punishment if applied the wrong way. Punishment refers to adding something aversive in order to decrease a behaviour. The most common example of this is disciplining (e.g. spanking) a child for misbehaving. We want to increase positive behaviour and food intake and emphasise that the child makes a choice and is not forced into a situation. There should be a neutral approach to the child, constantly repeating the options available. When the child reconsiders the choice and decides to eat, the avoidance situation (for example, resting in bed) is reversed. Another limitation concerns the kind of caregiver performing the training. Dieticians, speech therapists and child psychologists coach autistic children with selective feeding problems. However, with our method, we use laboratory diagnostics for our patients, and not all health care professionals have access to laboratories. We solved this problem in our region by coordinating between a pediatrician and other health care professionals like a dietician. In these cases the pediatrician only evaluates the health and deficiency status at intake, three months and six months. The other health care professional performs the actual training. These children are not evaluated yet in a study.

A further possible limitation of this study concerns parents who are not capable of applying the training in their home environment. This problem did not occur in our case, except for the patients who were excluded, but one can imagine that parents are not able to muster the required creativity and persistence. When this risk occurred, we decreased the interval of the visits to the pediatrician in order to allow the parents to feel more secure and provide them with a person they could fall back on. We also introduced a pediatric social worker who could visit the parents at home during meal times. For the children in this study, she was not needed, but we used her expertise for other children to support the parents when they found it difficult to proceed.

\section{Conclusion}

The teaspoon method, with its simple rules and consequences, effectively treats selective and restrictive feeding disorders in high functioning autistic children. The combination of parental participation, and a medical and psychological approach by a health care professional, is of great value. All children improved with regard to their quantitative and qualitative intake and this resulted in better health perspectives and growth parameters for the future. The variation of the 
selectively taken food groups increased. Parents could cook again for the entire family, without making exceptions for their child with the feeding disorder. These results were gained due to the hard work and persistence of the parents.

\section{References}

[1] Bandini, L.G, Anderson, S.E., Curtin, C., et al. (2010) Food Selectivity in Children with Autism Spectrum Disorders and Typically Developing Children. The Journal of Pediatrics, 157, 259-264. https://doi.org/10.1016/j.jpeds.2010.02.013

[2] Kodak, T. and Piazza, C.C. (2008) Assessment and Behavioral Treatment of Feeding and Sleeping Disorders in Children with Autism Spectrum Disorders. Child and Adolescent Psychiatric Clinics of North America, 17, 887-905, x-xi. https://doi.org/10.1016/j.chc.2008.06.005

[3] Schreck, K.A., Williams, K. and Smith, A.F. (2004) A Comparison of Eating Behaviors between Children with and without Autism. Journal of Autism and Developmental Disorders, 34, 433-438. https://doi.org/10.1023/B:JADD.0000037419.78531.86

[4] Piazza, C.C., Patel, M.R., Santana, C.M., et al. (2002) An Evaluation of Simultaneous and Sequential Presentation of Preferred and Nonpreferred Food to Treat Food Selectivity. Journal of Applied Behavior Analysis, 35, 259-270. https://doi.org/10.1901/jaba.2002.35-259

[5] Valleau, J.C. and Sullivan, E.L. (2014) The Impact of Leptin on Perinatal Development and Psychopathology. Journal of Chemical Neuroanatomy, 61-62, 221-232. https://doi.org/10.1016/j.jchemneu.2014.05.001

[6] Rodrigues, D.H., Rocha, N.P., Sousa, L.F., et al. (2014) Changes in Adipokine Levels in Autism Spectrum Disorders. Neuropsychobiology, 69, 6-10.

https://doi.org/10.1159/000356234

[7] Tang, B., Piazza, C.C., Dolezal, D. and Stein, M.T. (2011) Severe Feeding Disorder and Malnutrition in 2 Children with Autism. Journal of Developmental and Behavioral Pediatrics, 32, 264-267. https://doi.org/10.1097/DBP.0b013e3182138668

[8] Volkert, V.M. and Vaz, P.C. (2010) Recent Studies on Feeding Problems in Children with Autism. Journal of Applied Behavior Analysis, 43, 155-159. https://doi.org/10.1901/jaba.2010.43-155

[9] Herndon, A.C., DiGuiseppi, C., Johnson, S.L., et al. (2009) Does Nutritional Intake Differ between Children with Autism Spectrum Disorders and Children with Typical Development? Journal of Autism and Developmental Disorders, 39, 212-222. https://doi.org/10.1007/s10803-008-0606-2

[10] Manikam, R. and Perman, J.A. (2000) Pediatric Feeding Disorders. Journal of Clinical Gastroenterology, 30, 34-46. https://doi.org/10.1097/00004836-200001000-00007

[11] Herguner, S., Kelesoglu, F.M., Tanidir, C. and Copur, M. (2012) Ferritin and Iron Levels in Children with Autistic Disorder. European Journal of Pediatrics, 171, 143 146. https://doi.org/10.1007/s00431-011-1506-6

[12] Zimmer, M.H., Hart, L.C., Manning-Courtney, P., et al. (2012) Food Variety as a Predictor of Nutritional Status among Children with Autism. Journal of Autism and Developmental Disorders, 42, 549-556. https://doi.org/10.1007/s10803-011-1268-Z

[13] Anderson, S.E., Must, A., Curtin, C. and Bandini, L.G. (2012) Meals in Our Household: Reliability and Initial Validation of a Questionnaire to Assess Child Mealtime Behaviors and Family Mealtime Environments. Journal of the Academy of Nutrition and Dietetics, 112, 276-284. https://doi.org/10.1016/j.jada.2011.08.035 
[14] Hendy, H.M., Williams, K.E., Riegel, K. and Paul, C. (2010) Parent Mealtime Actions That Mediate Associations between Children's Fussy-Eating and Their Weight and Diet. Appetite, 54, 191-195. https://doi.org/10.1016/j.appet.2009.10.006

[15] Seiverling, L., Hendy, H.M. and Williams, K. (2011) The Screening Tool of Feeding Problems Applied to Children (STEP-CHILD): Psychometric Characteristics and Associations with Child and Parent Variables. Research in Developmental Disabilities, 32, 1122-1129. https://doi.org/10.1016/j.ridd.2011.01.012

[16] Piazza, C.C., Fisher, W.W., Brown, K.A., et al. (2003) Functional Analysis of Inappropriate Mealtime Behaviors. Journal of Applied Behavior Analysis, 36, 187-204. https://doi.org/10.1901/jaba.2003.36-187

[17] Najdowski, A.C., Wallace, M.D., Penrod, B., et al. (2008) Caregiver-Conducted Experimental Functional Analyses of Inappropriate Mealtime Behavior. Journal of Applied Behavior Analysis, 41, 459-465. https://doi.org/10.1901/jaba.2008.41-459

[18] Vaz, P.C., Volkert, V.M. and Piazza, C.C. (2011) Using Negative Reinforcement to Increase Self-Feeding in a Child with Food Selectivity. Journal of Applied Behavior Analysis, 44, 915-920. https://doi.org/10.1901/jaba.2011.44-915

[19] Dutch Nutrition Centre (2014) Age Appropriate Portions for Children. http://www.voedingscentrum.nl/nl.aspx

[20] Kearney, A.J. (2008) Understanding Applied Behavior Analysis, an Introduction to ABA for Parents, Teachers, and Other Professionals. Jessica Kingsley Publishers, London.

[21] Bachmeyer, M.H., Piazza, C.C., Fredrick, L.D., et al. (2009) Functional Analysis and Treatment of Multiply Controlled Inappropriate Mealtime Behavior. Journal of Applied Behavior Analysis, 42, 641-658. https://doi.org/10.1901/jaba.2009.42-641

[22] Seiverling, L., Williams, K., Sturmey, P. and Hart, S. (2012) Effects of Behavioral Skills Training on Parental Treatment of Children's Food Selectivity. Journal of Applied Behavior Analysis, 45, 197-203. https://doi.org/10.1901/jaba.2012.45-197

[23] Lewis, C.D., Traboulsi, E.I., Rothner, A.D. and Jeng, B.H. (2010) Xerophthalmia and Intracranial Hypertension in an Autistic Child with Vitamin A Deficiency. Journal of Pediatric Ophthalmology \& Strabismus, 48, E1-E3. https://doi.org/10.3928/01913913-20100318-04

[24] McAbee, G.N., Prieto, D.M., Kirby, J., Santilli, A.M. and Setty, R. (2009) Permanent Visual Loss Due to Dietary Vitamin A Deficiency in an Autistic Adolescent. Journal of Child Neurology, 24, 1288-1289. https://doi.org/10.1177/0883073809333541

[25] Tanoue, K., Matsui, K. and Takamasu, T. (2012) Fried-Potato Diet Causes Vitamin A Deficiency in an Autistic Child. Journal of Parenteral and Enteral Nutrition, 36, 753-755. https://doi.org/10.1177/0148607111436280

[26] Camargo Jr., C.A., Ganmaa, D., Frazier, A.L., et al. (2012) Randomized Trial of Vitamin D Supplementation and Risk of Acute Respiratory Infection in Mongolia. Pediatrics, 130, e561-567. https://doi.org/10.1542/peds.2011-3029

[27] Wu, A.C., Tantisira, K., Li, L., et al. (2012) Effect of Vitamin D and Inhaled Corticosteroid Treatment on Lung Function in Children. American Journal of Respiratory and Critical Care Medicine, 186, 508-513. https://doi.org/10.1164/rccm.201202-03510C

[28] Pogge, E. (2010) Vitamin D and Alzheimer's Disease: Is There a Link? The Consultant Pharmacist, 25, 440-450. https://doi.org/10.4140/TCP.n.2010.440

[29] Villamor, E., Marin, C., Mora-Plazas, M. and Baylin, A. (2011) Vitamin D Deficiency and Age at Menarche: A Prospective Study. The American Journal of Clinical Nutrition, 94, 1020-1025. https://doi.org/10.3945/ajcn.111.018168 
[30] Biancheri, R., Cerone, R., Schiaffino, M.C., et al. (2001) Cobalamin (Cbl) C/D Deficiency: Clinical, Neurophysiological and Neuroradiologic Findings in 14 Cases. Neuropediatrics, 32, 14-22. https://doi.org/10.1055/s-2001-12217

[31] Codazzi, D., Sala, F., Parini, R. and Langer, M. (2005) Coma and Respiratory Failure in a Child with Severe Vitamin B(12) Deficiency. Pediatric Critical Care Medicine, 6, 483-485. https://doi.org/10.1097/01.PCC.0000167565.30084.84

[32] Stabler, S.P. (2013) Clinical Practice. Vitamin $\mathrm{B}_{12}$ Deficiency. The New England Journal of Medicine, 368, 149-160. https://doi.org/10.1056/NEJMcp1113996

[33] Peirano, P.D., Algarin, C.R., Chamorro, R.A., et al. (2010) Sleep Alterations and Iron Deficiency Anemia in Infancy. Sleep Medicine, 11, 637-642. https://doi.org/10.1016/j.sleep.2010.03.014

[34] Peirano, P., Algarin, C., Chamorro, R., et al. (2012) Iron Deficiency Anemia in Infancy Exerts Long-Term Effects on the Tibialis Anterior Motor Activity during Sleep in Childhood. Sleep Medicine, 13, 1006-1012. https://doi.org/10.1016/j.sleep.2012.05.011

[35] Imdad, A., Mayo-Wilson, E, Herzer, K. and Bhutta, Z.A. (2017) Vitamin A Supplementation for Preventing Morbidity and Mortality in Children from 6 Months to 5 Years of Age. Cochrane Database of Systematic Reviews, No. 3, CD008524.

Submit or recommend next manuscript to SCIRP and we will provide best service for you:

Accepting pre-submission inquiries through Email, Facebook, LinkedIn, Twitter, etc. A wide selection of journals (inclusive of 9 subjects, more than 200 journals)

Providing 24-hour high-quality service

User-friendly online submission system

Fair and swift peer-review system

Efficient typesetting and proofreading procedure

Display of the result of downloads and visits, as well as the number of cited articles

Maximum dissemination of your research work

Submit your manuscript at: http://papersubmission.scirp.org/

Or contact ojped@scirp.org 